\title{
EDUCAÇÃO E FOUCAULT: UM DEBATE SOBRE SEXUALIDADE NO CONTO LITERÁRIO DE CHAPEUZINHO VERMELHO
}

\author{
Ravelli Henrique de Souza ${ }^{\mathrm{i}}$ \\ Marta Regina Furlan de Oliveira ${ }^{\text {ii }}$ \\ Geiva Carolina Calsa ${ }^{\text {iii }}$
}

\begin{abstract}
Resumo: Este artigo objetiva compreender sobre o conceito de sexualidade em Foucault a fim de identificar suas relações com o conto literário de Chapeuzinho Vermelho. O estudo se justifica pela necessidade do ensino do conceito de sexualidade em relação ao processo de como os corpos são normalizados na escola a partir da educação para infância, seja pela identificação e reprodução da repressão sexual e ou por intermédio de contos literários pré-estabelecidos. A metodologia é de cunho teórico em torno do referencial foucaultiano e, de autores que dialogam com a temática sobre a sexualidade e, ainda análise do conto literário infantil. Este texto é um recorte da dissertação de Mestrado apresentada ao Programa de Pós-Graduação em Educação da Universidade Estadual de Londrina e da participação no Projeto de Pesquisa intitulado "Semiformação e educação no contexto da sociedade danificada" da respectiva universidade. Os resultados direcionam para a necessidade de uma melhor compreensão dos contos literários utilizados nas instituições educativas voltadas à infância, em específico o de Chapeuzinho Vermelho, no sentido de propiciar estratégias de ensino mobilizadoras para o desenvolvimento do pensar e agir crítico à luz da construção de subjetividades operantes e, ainda, ampliar o olhar e discussão acerca da diversidade sexual a partir do direito e da vontade de ser e saber nos espaços escolares.
\end{abstract}

Palavras-Chave: Educação; contos literários; Foucault; sexualidade.

\section{EDUCATION AND FOUCAULT: A DEBATE ON SEXUALITY IN THE LITERARY TALE OF LITTLE RED RIDING HOOD}

\begin{abstract}
This article aims to understand the concept of sexuality in Foucault in order to identify its relations with the literary tale of Little Red Riding Hood. The study is justified by the need to teach the concept of sexuality in relation to the process of how bodies are normalized in school from childhood education, by either the identification and reproduction of sexual repression and or through preestablished literary tales. The methodology is of a theoretical nature around the Foucauldian framework and, of authors who dialogue with the theme on sexuality and, still, analysis of the children's literary tale. This text is an excerpt from the Master's dissertation presented to the Graduate Program in Education at the State University of Londrina and from the participation in the Research Project entitled "Semiformation and education in the context of damaged society" at the respective university. The results point to the need for a better understanding of the literary tales used in educational institutions focused on childhood, specifically the Little Red Riding Hood, in order to provide mobilizing teaching strategies for the development of critical thinking and acting in the light of the construction of subjectivities operant and, still, to broaden the look and discussion about sexual diversity from the right and the will to be and know in the school spaces.
\end{abstract}

Keywords: Education; literary tales; Foucault; sexuality.

\section{Introdução}

O presente texto parte de uma reflexão acerca da normalização sexual no conto literário de 
Chapeuzinho Vermelho, sendo desse modo, um recorte de estudo e pesquisa ${ }^{\text {iv }}$ desenvolvidos no Programa de Pós-Graduação - Mestrado em Educação da Universidade Estadual de Londrina e da participação no Projeto de Pesquisa intitulado "Semiformação e educação no contexto da sociedade danificada" da respectiva universidade.

O conto literário de Chapeuzinho Vermelho possui grande circulação no meio educacional infantil. Nosso interesse neste estudo se deve ao contexto social contemporâneo marcado por mecanismos de controle e cuidados de si e do outro. Nesta análise procuramos mostrar quanto os padrões patriarcais e disciplinadores do século XIX trazem indicadores importantes para compreender a circulação do ideário de príncipe e princesa ainda neste início do século XXI. Nossa hipótese é a de que contos literários como Chapeuzinho Vermelho podem potencializar as marcas de gênero e sexualidade por normas, valores e padrões de comportamento hegemônicos na sociedade brasileria.

Nesse sentido, a linguagem textual do conto traz personagens emblemáticos que representam uma concepção de sexualidade que perpetua masculinidades e feminilidades normativas. Normatividade que mantem uma perspectiva binária de luta entre "o bem" versus o "mal", o certo e o errado, e, em particular nos contos de fadas que circulam na educação infantil, o final "viveram felizes para sempre" (FILHA, 2011).

Desde a educação para a primeira infância, compreendida pela faixa etária entre 0 a 5 anos até a universidade, extraímos leituras críticas e pós-críticas do respectivo conto em que as questões de sexualidade revelam certa ideologização ao impor que meninos e meninas tenham comportamentos associados aos principescos, pelo construto das identidades masculina e feminina associadas a padrões e regras comportamentais padronizados e cristalizados à luz do contexto social.

Sendo assim, o equipamento teórico foucaultiano é essencial uma vez que estamos inseridos em uma sociedade submetida ao poder disciplinar que, em concordância com Foucault (1996), está associado a uma rede de relações peculiares envolvidas em ditames normativos e artimanhas morais. Então, como problema de pesquisa, questionamos: Como são constituídas as relações de sexualidade no contexto da educação para a infância a partir do conto literário Chapeuzinho Vermelho?

A partir da problemática, temos como objetivo geral compreender o conceito de sexualidade em Foucault a fim de identificar suas relações com o conto literário de Chapeuzinho Vermelho. Os objetivos específicos são: a) compreender a história da repressão sexual a partir do século XVII; b) analisar e refletir, em Foucault, sobre as relações de sexualidade presentes no conto literário de Chapeuzinho Vermelho e possíveis inferências no que tange ao processo de formação de professores para a infância (educação infantil e anos iniciais do ensino fundamental).

A metodologia é uma revisão bibliográfica pelas lentes de Foucault, especificamente com a obra intitulada de "A História da Sexualidade" (2015). Substancialmente consideramos os próprios estudos de 
Foucault (2014, 2017) e de estudiosos como Candiotto (2013), Witzel (2012), Gross (2018), Pinto (2006), Corso e Corso (2006) e outros autores que dialogam com a respectiva teoria. A versão do conto Chapeuzinho Vermelho selecionada para nossa análise é a de 2018 publicada pela editora Fábula.

Em Foucault há a possibilidade de um descortinar do olhar, pelo viés de uma nova proposta de desconstrução e reposição dos padrões normativos, uma vez que o conto é um documento histórico, sendo também um artefato cultural e educacional pertencente à cultura educacional e formativo enquanto estratégia do ensino pelo caminho literário. O conto possibilita perceber, pelas entrelinhas, regras e padrões de comportamento provenientes de costumes de sua época e direcionar, no caso, o conto analisado, para um ideal de feminilidade e masculinidade em relação a sexualidade das personagens envolventes. Para além da rasa reprodução da violência dos corpos infantis, há maneiras diversificadas de comportamentos em consonância com as subjetividades humanas. E, diante disso, há a busca da vontade de saber em educandos e professor(es) pelo cuidado de si que torna-se imprescindível.

Iniciamos nosso texto com uma introdução à discussão sobre sexualidade e repressão sexual, logo após, nossa discussão sobre o conto Chapeuzinho Vermelho à luz do referencial teórico.

\section{Sexualidade: um dispositivo normativo ou uma ciência discursiva?}

Ao comparar as relações de sexualidade do século XVII com o século XIX, Michel Foucault inquietou-se com os moldes repressivos das épocas, no sentido de esclarecer as inter-relações imperiais normativas entre homem e sociedade que causaram a coerção sexual com a hipocrisia e o silêncio. A sessão objetiva investigar sobre o conceito de sexualidade à luz das proposições teóricas de Michael Foucault, com a discussão sobre a repressão do poder e da sexualidade, principalmente com a respectiva obra: A História da Sexualidade (2015). Tendo em vista que essa obra foi selecionada com o intuito de esclarecer a problemática posta em questão para que possamos localizar as possíveis possibilidades de subvertermos a repressão sexual imposta, principalmente nos corpos infantis na escola.

A repressão dos impulsos causada pelos ideais normativos do século XVII criou a ideia de perfeição em que a violência se estabeleceu preponderantemente. Sobre esse assunto Foucault (2015, p. 7) afirma: "Gestos diretos, discursos sem vergonha, transgressões visíveis, anatomias mostradas e facilmente misturadas, crianças astutas vagando, sem incômodo nem escândalo, entre os risos dos adultos: os corpos pavoneavam" eram fortemente reprimidos pela força do estado. Ao usar o verbo pavonear o autor acentua o sentido escandaloso e transgressor do uso dos corpos que buscam ser encerrados pela ordenação social, em um contexto que se organiza cada vez mais para contingenciamento do sexo à reprodução por meio do casamento. Para o autor, portanto, a sexualidade pode ser considerada um dispositivo normativo da sociedade burguesa. 
Ainda que sua política de (r)existência se faça presente em tempos contemporâneos, a sexualidade pode ser legitimada como uma ciência discursiva proveniente de elementos culturais que produzem vontades. No entanto, afirmamos a necessidade de se reiniciar a sexualidade que fora cancelada a partir de novos olhares, tendo como parâmetro de análise a compreensão de como a mesma foi utilizada como objeto de repressão permanecendo até os dias atuais.

Foucault (2015), nesse sentido, nos provoca a pensar acerca dos dispositivos normativos sociais de que aquilo que não é disposto conforme as regras ou modificado pela geração não se veicula a um sentido racional, apenas reduz ao silêncio, tendo como exemplo: a repressão sexual imposta às crianças desde a primeira infância. Por não ter sexo e nem sexualidade definida, os pequenos são interditados desses mecanismos de poder por meio de discursos normalizadores que impõem um sistema de silenciamento coletivo e que, aplicado individualmente, faz verídico o funcionamento da repressão com a condenação e o desaparecimento da sexualidade perante a influência coercitiva das leis ordenadoras que têm como objetivo principal, mascarar a vontade de ser e saber.

Esses corpos se fluem pelo espaço e materializam as normas estabelecidas perante seu sexo biológico, com a submissão e obediência de pura coerção: “obedecemos àquele que tem nas mãos a arma ou o chicote, a força de decisão sobre a carreira e mesmo sobre a vida e a morte" (GROS, 2018, p.38).

Gros (2018, p. 38) em sua obra Desobedecer acrescenta: “ser submisso é ser prisioneiro de uma relação de força que subjuga, domina, aliena no sentido literal. Submisso, estou sob a inteira dependência do outro, que comanda, decide, grita ordens, acaba com você e destrói as vontades”. Esse sentido é de suma importância para a escola, pois compreende os delineamentos não normativos dos corpos que já são impostos. Assim, as instâncias sociais necessitam entender os corpos como importantes condutores de direitos humanos.

Se no cadinho do século XVII a repressão foi de feitio imprescindível entre a relação poder, saber e sexualidade, agora é necessário transgredir as leis coercitivas e criar uma economia dos mecanismos de poder vinculada à política, no sentido de limparmos o verniz da paz civil. Por conseguinte, por mais intransigente que seja o discurso conformista perante a ordem ele se sustenta aos espécimes reguladores, dando origem, segundo Foucault (2015) ao século XVII como a Idade da Repressão para que o capitalismo se desenvolvesse no decurso da ordem burguesa tornando o sexo como uma crônica fútil e vexaminosa a se dissipar.

Faz-se necessário a quebra desse paradoxo relacionado à repressão sexual, a fim de usar a transgressão inversamente e romper com esse modelo de sistema falho que, cada vez mais atrofia a proclamação da liberdade e do direito sexual e das sexualidades em detrimento do abuso de poder entre sexo, pecado e condenação. 
A colocação do sexo em discurso permite a validade do estudo sobre a sexualidade como algo ainda a se definir, de maneira fluida e culturalmente construída. Neste estudo, articulamos com a questão sobre o poder, no sentido de compreender a constituição do poder, bem como a utilização de determinadas formas e condutas relacionadas ao controle do prazer cotidiano. Para esse processo reflexivo e de indagação, há a necessidade de que o fio condutor esteja relacionado ao discurso fundamentado na vontade de saber sobre a história da sexualidade e a repressão sexual postas por Foucault.

Para melhor esclarecimento, assim como Foucault, não pretendemos "afirmar que o sexo não tenha sido proibido, bloqueado, mascarado ou desconhecido desde a época clássica; nem mesmo afirmamos que a partir daí ele o tenha sido menos do que antes" (FOUCAULT, 2015, p. 17). Assim como Silva (2017) entendemos que "o sexo é político, pois contém uma relação de poder”. O problema está em fazer da interdição do sexo um elemento fundamental para escrever a história do que foi dito sobre ele. Dessa maneira, a partir do processo de disseminação e implantação das sexualidades polimorfas pretendemos esclarecer que a vontade do saber não se detém diante de tabus, mas se pauta em construir a sua própria ciênciav .

Ainda no século XVII a carne torna-se a origem de todos os pecados e os novos pudores são tidos como insultos e zombarias no processo de inversão de valores no exercício do poder, principalmente, com a incitação da fala cada vez mais relacionada ao sexo e articulação com o desejo.

Um discurso sancionado transmite pela linguagem a menção indireta do sexo adequando a abjeção entre corpo e alma, tornando-o congruente à neutralidade. Na transição do século XVII para o século XVIII a pastoral fez a colocação do sexo em discurso como uma regra fixa para todos, até mesmo os cristãos, por ora, na confissão ideal obrigatória. "Coloca-se um imperativo: não somente confessar os atos contrários à lei, mas procurar fazer de seu desejo, de todo o seu desejo, um discurso" (FOUCAULT, 2015 , p. 23). A pastoral do século XVIII, agora reformada, ainda que de um modo discreto, também estabeleceu as regras discursivas do sexo com uso de feitios morais e de dispositivos suplementares, com o propósito de justificar o sexo e a sujeição sexual útil e aceitável dentro de um preceito de construção binária e tradicional da família.

Foucault (2015) deixa explícito em seus estudos sobre a sexualidade que, por interesse público, nasce, ainda no século XVIII, um discurso técnico, político e econômico para se falar sobre o sexo, ignorando toda a teoria geral da sexualidade. O discurso então ignora a moral para se pautar na racionalidade determinante de fator biológico, precisando que esses efeitos ordenadores sobre o discurso do sexo sejam, necessariamente, superados:

Deve-se falar do sexo, e falar publicamente, de uma maneira que não seja ordenada em função da demarcação entre o lícito e o ilícito, mesmo se o locutor 
preservar para si a distinção (é para mostrá-lo que servem essas declarações solenes e liminares); cumpre falar do sexo como de uma coisa que não se deve simplesmente condenar ou tolerar, mas gerir, inserir em sistemas de utilidade, regular para o bem de todos, fazer funcionar segundo um padrão ótimo. O sexo não se julga, apenas, administra se (FOUCAULT, 2015, p. 27).

O sexo, sob essas ideias de Foucault, deve ser administrado diante discursos que o veja como uma temática útil e saudável para o bem populacional, tendo em vista que independente de orientação sexual e das formas de se conseguir prazer o sexo não é mais uma categoria de julgamento ou de tolerância, ele faz parte da vida e está implícito às questões de saúde e bem-estar humano. Ao nos educarmos sexualmente, nos permitimos entender sobre o sexo, sobre o corpo e principalmente sobre nós mesmos, descobrir quais são nossos limites e extensões e enxergar o outro com quem nos relacionamos. Falar sobre sexo nos propõe refletir e conscientizar sobre os tabus sociais e morais a fim de nos libertarmos de toda a pressão sexual que foi posta em nossa sociedade.

Ao colocar em discurso a problematização do sexo no século XVIII, o governo explicita sua despreocupação com as individualidades, dando ênfase ao coletivo, pois, a preocupação dessa instituição de poder nesse momento é a de controlar os corpos para que se obedeça às imposições postas em um sistema de vigilância e punição. Logo, cada instituição disciplinar responsabilizou-se por determinada necessidade coletiva, provocando, desse modo, um grande incomodo político e econômico da população. É possível afirmar que para que um país se desenvolva o mesmo deve ser povoado pela análise social pautada coletivamente em como cada indivíduo faz seu sexo. Assim, o discurso passa a priorizar a conduta sexual populacional como objeto de investigação e estatística.

A economia política populacional focaliza, então, observações sobre o sexo pautadas em análise das condutas e determinações entre os fatores: biológico, econômico e os meios tradicionais relacionados à moral e à religião, com o intuito de controlar as práticas sexuais para a procriação. Logo, o sexo se torna objeto de disputa pública, necessitando que haja o fortalecimento do discurso sobre o sexo pelas forças coletivas e individuais, a fim de potencializar os ditames estatais, a política pública de servir à felicidade geral em relação às dicotomias lar/trabalho e cuidados/saúde.

Para Foucault (2015), o discurso sobre o sexo tem se multiplicado há mais de três séculos inibindo a possibilidade de garantir a solidez e a imprudência sexual mediante os discursos perversos. Não obstante, a medicina no século XIX tenta reivindicá-lo, poderes e prazeres, para assegurar o pensamento binário pautado em um determinismo biológico sobre a fisiologia da reprodução animal e vegetal. Tal defasagem, quando comparada a discursos sobre a sexualidade humana faz uso da exclusão de todo conhecimento historicamente construído para encaixar o sexo como obediente no dispositivo da normatividade. 
A resistência fundamental em oposição à enunciação do discurso sexual se destina ao impedimento da verdade e da vontade de saber, gerando uma vontade obstinada de não saber. Dessa maneira, o discurso científico sobre o sexo no século XIX se pauta em ofuscações sistemáticas, o desinteresse de ver e ouvir. Ao mascarar o sexo se cria uma relação fundamental com a verdade, são táticas desviadoras para dar forma à determinada petição do saber, da forma que, não querer é uma vicissitude da vontade axiomática.

O importante é que o sexo não tenha sido somente objeto de sensação e de prazer, de lei ou de interdição, mas também de verdade e falsidade, que a verdade do sexo tenha se tornado coisa essencial, útil ou perigosa, preciosa ou temida; em suma, que o sexo tenha sido constituído em objeto de verdade (FOUCAULT, 2015, p. 63).

Para Foucault o sexo se constitui em torno de um pedestal dos discursos descriminalizadores da verdade. Nesse sentido, podemos afirmar que a verdade sobre o sexo tem sido produzida mediante dois grandes procedimentos: a sociedade dotada da arte erótica, em que a verdade é extraída do próprio prazer e sua prática não permite a experiência e a confissão que passou a ser uma das técnicas mais valorizadas dentro do propósito da verdade no Ocidente.

Diante disso, temos construído uma história marcada pelo discurso 'correto' do sexo, ou seja, falamos da temática, porém, mesmo com a linguagem coloquial do sexo, ainda de forma constrangedora e autoritária. Souza (2015) ao referir Foucault nos mostra como esse autor desconstruiu a verdade repressiva dos sexos através da incitação dos discursos, sendo que essa verdade repressora ocorreu e ocorre pela junção qualitativa-quantitativa em intensificar os padrões de comportamentos a serem seguidos e as punições. De forma que, essa hierarquia se formou pela junção de instituições de poder, tais como, a pastoral cristã, o direito canônico e a lei civil que regiam e delimitavam o proibido do permitido. “A política do sexo é a necessidade de controlar o sexo através do discurso, de discipliná-lo, de gerir enunciados úteis" (SOUZA, 2015, p. 3).

Diante de todo o discurso sobre a verdade do sexo, finalmente entendemos a sexualidade de acordo com Foucault (2015, p.77) como "o correlato dessa prática discursa desenvolvida lentamente, que é a scientiasexualis. Ou seja, não é uma ideologia, mas sim, a produção da verdade através do discurso. Contra o determinismo biológico, a sexualidade é uma economia que convém à interseção de um domínio penetrável e fluído no campo de significações a se decifrar pela infinitude das relações causais. A necessidade de sua performatividade esclarece o funcionamento e os efeitos do poder sobre os corpos que se veiculam, tornando-se uma ciência pautada na história dos discursos cultural e politicamente produzidos com base na difusão e desdobramentos dos prazeres inerentes à construção do rigor sexual. 
A sexualidade durante séculos foi considerada como biológica em relação ao corpo e ao sexo, sendo controlada nas instituições disciplinares em que as normas tentam moldar os comportamentos de meninos e meninas, porém com as mudanças sociais e novas formas de pensamentos ela "não deixa de ser um produto histórico e sociocultural, modelado em situações sociais reais. É alvo de controle por várias instituições sociais (família, igreja, escola), incluindo-se, ainda, os livros didáticos e paradidáticos" (SOARES; RINCON, 2017, p. 74).

Ainda no século XXI as necessidades do estado e do capital ainda exigem a organização binária referente à sexualidade para que se mantenha valores patriarcais antigos e repressivos a fim de continuar o controle sobre os corpos, mas ao tentar marginalizar e/ou excluir subjetividades que fogem do binário a instituição estatal se permite a falha, pois esses corpos existem e mesmo que o discurso disciplinar sobre a sexualidade tenha grande influência nas esferas sociais, tais como, igreja, família e escola, essas mesmas instituições, principalmente a escola em que damos ênfase nesse artigo, a partir do discurso crítico em Foucault podem colaborar para a manutenção e expansão desses valores a fim de subverter as normativas repressoras e entender as subjetividades humanas como plurais.

\section{Percurso metodológico: da escolha do conto à análise crítica em Foucault}

Neste estudo optamos discutir a metodologia por intermédio da análise do equipamento bibliográfico foucaultiano proposta por Michel Foucault em "A arqueologia do saber" (2017) e "A ordem do Discurso" (2014) e de seus estudiosos e outros autores que dialogam com essa base teórica ${ }^{\mathrm{vi}}$. O processo investigativo é construído a partir das relações do poder atreladas à sexualidade no conto literário intitulado de "Chapeuzinho Vermelho" que, de certa forma, é cotidianamente trabalhado na educação escolar para a infância (educação infantil e anos iniciais) por intermédio de didáticas de ensino e estratégias pedagógicas associadas à leitura e à oralidade na narrativa pelas crianças. Na escola, desse modo, o conto é repassado, na maioria dos casos, por intermédio da reprodução oral e escrita do texto (desenho ou interpretação técnica da história), desconsiderando a experiência do pensar crítico e emancipatório do saber.

Esse conto literário é, arqueologicamente, construído mediante a estruturação da sociedade patriarcal francesa e, escrito por Perrault no século XVII e, logo depois pela sociedade protestante alemã no início do século XIX com os irmãos Jacob e Wilhelm Grimm. O objetivo, segundo a análise foucaultiana, consiste em governar e violentar corpos (masculinos e femininos) por meio da regulação do pensamento, consolidando, desse modo, uma sociedade disciplinarmente ajustada às normas, valores e determinadas formas de comportamento. Para essa análise crítica e reflexiva do conto, atrelamos aos 
conceitos foucaultianos: a) relações de poder circular; b) governamentabilidade; c) sociedade disciplinar e d) violência dos corpos.

A escolha por essa interpelação teórica está relacionada às questões fatídicas que comprovam toda a era de repressão, dos jogos de poder, das atribuições de papéis e da disciplinarização dos corpos que, de certa forma, efetivaram a história da sexualidade, ao reproduzir comportamentos e práticas discriminatórias, idealizadoras em relação ao gênero e à escolha sexual de seres. Assim, a escolha sexual é caracterizada segundo o sexo às margens das relações sociais do binarismo normativo patriarcal. Esse conto foi estruturado, readaptado e reorganizado para continuar a propagação da violência por intermédio de relações de poder, sendo elas sutis ou não.

Pelas lentes do pensamento crítico e emancipatório, há a urgente necessidade de ressignificação interpretativa do texto para além dos "clichês pedagógicos" que utilizam da reprodução servil e moralista do saber. Atuando na filosofia, na ciência, na política, na moral, Candiotto (2013) afirma que a atitude crítica é a arte de não ser governado, possibilitando ao sujeito social refletir sobre as questões atribuídas ao seu redor em prol de uma tomada de atitude cabível de acordo com seus ideais e conhecimentos e, ainda, atuar na defesa dos direitos humanos e universais diante dos abusos do estado.

Não querer ser governado dessa ou daquela maneira implica também a renúncia em aceitar incondicionalmente algo como verdadeiro porque a autoridade diz que é verdadeiro. $\mathrm{O}$ discurso da autoridade merece aceitação apenas se houver boas razões e se o cidadão estiver convicto de que o que lhe é proposto, de fato, é verdadeiro. Desse modo, o ponto de sustentação da crítica consiste em opor a certeza que advém do conhecimento científico em face da autoridade (CANDIOTTO, 2013, p. 115).

Para Foucault, a crítica começa seu percurso pela análise dos mecanismos de poder que requisitam discursos de verdade para justificar-se e legitimar-se, sendo que, segundo Candiotto (2013, p. 116) "tratase de uma atitude diferente de pensar, de agir e de sentir o mundo", com ações de estranhamento em relação às verdades fundadas no conhecimento objetivo do indivíduo, situando-as na dramatização de sua historicidade e, observadas nas práticas de governamentalização.

Foucault (2017, p. 53) revela a necessidade de compreensão crítica dos contos como documentos históricos que precisam ser tratados arqueologicamente como um conjunto de "relações entre as normas familiares, sexuais, penais, do comportamento dos indivíduos" e, que possuem um caráter restritivo que delimita o que é "normal" tornando o abjeto (desprezível) como propenso às punições e ao castigo. Witzel (2012, p. 185) comunga que "os contos irrompem como resultado de relações de poder que constroem, destroem e reconstroem, ao longo da história, verdades sobre o sujeito, e consequentemente [...] as identidades de gênero".

Em Witzel (2012) esses discursos singularizam as identidades de gênero, principalmente, a feminina, de modo que forja interditos, sanções, vigilância e punições nas tramas da microfísica do poder, 
regendo condutas e reconstruindo velhas identidades que se repetem e se deslocam na história dos discursos, apontando a mulher como um sujeito assinalado pelo determinismo sexual.

Os contos de fadas, geralmente, deixam clara a relação inerente entre a história, o sujeito e o discurso. Ressoam discursos ecoados da história, principalmente das mulheres, ao argumentar os perigos da liberdade feminina, apontando-as como merecedoras da violência causada em seus corpos, caso escolham a opção de agir por livre e espontânea vontade (WITZEL, 2012). Dessa maneira, faz-se necessária a análise do método arqueológico foucaultiano para reconstituir o discurso por intermédio de uma rede de práticas e estratégias discursivas relacionadas ao poder-saber e aos discursos já ditos no conto de Chapeuzinho Vermelho.

No tocante ao trabalho pedagógico do respectivo conto em ambientes escolares, há a prevalência de um ideal moralizante e de um discurso normatizador de conduta das mulheres (Chapeuzinho e a Avó) para a vida em sociedade. Trata-se de um conto que é construído por uma lógica "que coloca no centro das preocupações e no foco dos olhares vigilantes do século XXI o que os sujeitos têm de mais íntimo: sua sexualidade" (WITZEL, 2012, p. 182). A sexualidade, então, pela interpretação do texto revela as relações de poder e saber sobre os corpos de homens e mulheres independentemente de serem binários ou não binários.

No que tange à essencialidade dessa análise, Pinto (2006) afirma que é verdadeira e sem manipulação, uma vez que, provém da natureza dos sentidos. Em Foucault (apud PINTO, 2006) há a evidencia da teoria dos sentidos e das significações, visto que analisa a verdade como construção discursiva por meio de uma estrutura ou acontecimento existencial no processo de fixação dos sentidos de uma história contínua. O discurso, então, busca o êxito na fixação de maneira provisória e sem garantia de uma verdade objetiva (para sempre).

Pinto (2006) revela-nos que há discursos falsos e manipulados pautados em uma única verdade ditada por alguma instituição de poder ou por alguém que se vê somente enquanto objeto (objetificação). Nesse sentido, a construção da interpretação discursiva provoca efeitos concretos em relação aos significados incorporados pelos sujeitos que constroem ou são subjetificados. Esses efeitos estão associados às pessoas que se relacionam entre si, bem como os rumos que a história toma.

Assim,

O sentido da provisoriedade tem de ficar bem claro: não se trata de uma condição de constante mudança, mas que sinaliza que se não lutarmos todos os dias para que os nossos direitos continuem sendo direitos, nós podemos perdê-los. Porque aquela cláusula pétrea que diz todos nós temos o direito à vida foi um acordo construído discursivamente. Ou seja, se não lutarmos por isto, nós podemos perder este direito. Porque este é apenas um discurso provisório, com êxito, mas arbitrário (PINTO, 2006, p. 82). 
Diante disso e, urgidos pela busca da condição enquanto seres subjetivos inseridos nesse contexto social contemporâneo, buscamos desenvolver uma análise interpretativa discursiva do conto literário de fadas, especificamente, de "Chapeuzinho Vermelho" que, de certa forma, perpetua valores em suas narrativas, determinações de cenários, vestuários dos personagens, relações e conceitos pré-estabelecidos. Por esse viés, o discurso no texto literário tem sido pensado à luz de questões éticas e comportamentais vigentes em sintonia com os aspectos históricos e sociais do discurso. Pinto (2006, p. 84) reitera que "isso é uma tarefa para compreender os espaços, onde atores, partidos, movimentos atuam, agem e modificam a vida contemporânea”.

\section{Uma análise foucaultiana do conto "chapeuzinho vermelho"}

O conto literário denominado de "Chapeuzinho Vermelho" retrata a história de uma pequena menina "doce e inocente" e de sua avozinha que, diante da relação com o lobo mau, tiveram consequências ruins: foram engolidas por ele. É um dos clássicos lidos e contados nas instituições escolares destinadas à educação de crianças entre 0 a 10 anos e, portanto, é digna a análise, principalmente, no que tange à sexualidade presente no texto. Como os contos de fadas são contos populares, passados de geração à geração, existem várias versões diferentes, sendo que a versão mais recente está associada à produção escrita pelos Irmãos Grimm (2018) com a reviravolta surpreendente e surreal no final da história.

De acordo com Redel e Martiny (2015, p. 78) o conto de Chapeuzinho Vermelho se tornou popular em todo o mundo devido "à capacidade da literatura arquivar, registrar e estabelecer diálogos de um país ao outro, de uma geração à outra”. Em seu nível cultural, teve diversas apropriações que fizeram se manter vivo durante todas essas décadas e, em constante processo de (re)atualização.

Segundo as análises realizadas por Corso e Corso (2006), a versão produzida pelos Irmãos Grimm (2018) desvela que quase todas as versões desse conto contêm um drama temático de "devoração" e "perda da inocência”, uma vez que Chapeuzinho Vermelho é uma criança ingênua que desconhece sobre o sexo. Por meio dos prazeres da vida, como comer e brincar, ela transita entre a inocência infantil à informação sobre a existência de práticas sexuais adultas que surgem na vida das crianças, geralmente, por intermédio de seduções e/ou manipulações que podem provocar traumas infantis ${ }^{\mathrm{vii}}$.

Witzel (2012) qualifica Chapeuzinho Vermelho como: submissa, frágil, seduzida, portadora de uma beleza pueril e natural. Ainda, o conto apresenta marcas de erotismo e, tem três elementos que operam como núcleo da narrativa: prazer, sedução e sexualidade. $\mathrm{O}$ erotismo se manifesta por meio das proposições amorosas que constituem em um jogo linguístico do velar e desvelar, em que a união dos amantes, mesmo que não de acordo com um dos personagens, não fere a moral social burguesa, tendo em 
vista que, no contexto erótico, os aspectos sexuais são demasiadamente implícitos e levam em conta o prazer sexual, a sedução e a paixão dos amantes (SOARES; RINCON, 2017).

Para uma análise mais fidedigna sobre o conceito de sexualidade presente no texto literário, optamos por separar a história em trechos e analisar "partes" de seu todo que evidenciam as relações de poder e sexualidade de maneira explícita, a fim de possibilitar novas reflexões sobre o conto, principalmente no contexto educacional e formativo.

O primeiro trecho que escolhemos para a análise, é um dos mais impactantes do conto, de modo que:

Chapeuzinho andou por muito tempo colhendo flores e só parou quando não cabia mais nenhuma em suas mãos. Depois foi para a casa da avó. Estranhou que a porta estivesse aberta e quando entrou achou tudo tão esquisito que pensou: "Ai, meu Deus, por que estou com essa sensação estranha de medo? Eu sempre gosto tanto de estar na casa da vovó". Então foi até a cama, abriu o cortinado e lá estava a avó com a touca enfiada na cabeça, cobrindo o rosto, com um aspecto estranho. "Oi, vovó! Mas que orelhas grandes você têm!" "É para te ouvir melhor." "Vovó, mas que olhos grandes você têm!" "é para te ver melhor." "Vovó, mas que mãos grandes você tem." "É para te agarrar melhor!" "Mas, vovó, que terrível boca enorme é essa?" "É para te comer melhor." E com isso o lobo saltou da cama, pulou sobre a pobre Chapeuzinho e a engoliu (GRIMM, 2018, p. 106-107).

A passagem da história acontece no momento em que o percurso narrativo sai do decurso de manipulação e de competência (querer, saber, poder, dever) e realiza a performance (ação), reduzindo a narrativa ao objeto de valor. Chapeuzinho Vermelho é curiosa e sempre aguça seu desejo no processo de descoberta das coisas, fato esse narrado com a sua chegada na casa da avó. Envolvida pela curiosidade, procura entender o motivo das mudanças no corpo de sua avó recorrendo, desse modo, ao uso dos quatro sentidos (audição, visão, tato e paladar) enquanto estratégia de compreensão do novo.

Se na sociedade existem homens que buscam satisfazer seus desejos sexuais, logo o lobo é uma metáfora. Em Redel e Martiny (2015) a performance de Chapeuzinho Vermelho e os acessórios utilizados no enredo, potencializam-nos ao processo de entendimento de uma possível representação simbólica do sexo. Assim, a beleza da menina com sua capa vermelha torna-se um atrativo sexual de destaque em relação a sua avó; visto que o lobo demora para devorá-la enquanto está envolvido pela sedução e erotismo. A sexualidade aqui é remetida a dois elementos: a cor vermelha supõe o erotismo do contexto e o verbo "comer" interligado no diálogo de Chapeuzinho com o lobo. Ela o indaga: "Que boca grande você tem?" Pergunta rapidamente respondida pelo lobo: "É para te "comer". Aqui é possível uma interpretação associada ao ato sexual e, não necessariamente ao ato de ingerir algum tipo alimento, assim como ressaltam Redel e Martiny (2015).

Fundamentado em Foucault, Witzel (2012) complementa que é possível distinguir que as questões sobre bondade e ingenuidade da menina conduziram-na a sua morte e, ainda, à ignorância relacionada à 
vontade de saber. O autor reflete que, por conta desse desconhecimento sobre si, o sujeito em questão se torna uma vítima em relação ao lobo que aplica a penalidade perante a inocência da menina, prevalecendo os jogos de verdade propostos por Foucault que "definiram, desde os primórdios, a tradição dissimetria na relação entre os sexos e instauraram os códigos de sociabilidade daquela época" (WITZEL, 2012, p. 189).

À vista disso, Witzel (2012) profere que esses códigos estabeleceram as regras de condutas de não pertencimento em relação aos corpos femininos, logo o "lobo" poderia usufruir o quanto desejasse, considerando, pelo viés da família patriarcal, o pertence do "macho" sobre a "fêmea" para procriação de filhos. Os corpos das mulheres tornam-se subjugados por meio de "verdades sociais" provenientes de valores progressistas que naturalizam os desejos do "lobo mau" considerando a necessidade de se satisfizer sexualmente pela violência contra o sexo oposto.

Ao perceber as diferentes características da avó (olhos, orelhas e bocas grandes) representada pelo lobo, Chapeuzinho permanece no local indagando-a sobre esses novos atributos até que seja devorada por ele. Para Corso e Corso (2006, p. 54), esse diálogo "trata-se de uma conversa de mútua sedução, plena de preliminares", uma vez que o lobo a partir desta dupla violência, com a neta e a avó, é considerado como um violentador fetichista e eleva a proibição moral social ao extremo, principalmente, ao abuso de mulheres consideradas não sexuadas (crianças e idosos). Essa inocência curiosa relacionada à infantilidade da menina, para o abusador é uma forma de sedução que faz com que o mesmo desenvolva a violência de forma primitiva em sintonia com as relações de poder disciplinares.

A sexualidade infantil explicitada no conto literário associa-se com a "sexualidade pessoal" exercida corporalmente na transição da vida infantil para a adolescência. Como a criança não entende a violência, ela se torna extremamente refém dessa situação abusiva, mesmo que seja um menino, ele não perderá sua masculinidade, mas será considerado feminizado, uma vez que, tradicionalmente, essa violação é vista como uma entrega sexual feminina (CORSO; CORSO, 2006).

A avó, por sua vez, sempre "mimou" a criança, conforme a narrativa revelada: "nada havia que ela não houvesse dado a menina” e, até uma capa vermelha atraente costurou para sua neta. Ao associar a cor vermelha às representações sociais tanto da época quanto na atualidade, é possível deduzir uma aproximação ao processo natural da mulher (menstruação) com o período de maturação da menina. Ora, Corso e Corso (2006) elucida que a capa vermelha que não era simplesmente uma peça de vestimenta, mas sim, um produto de erotização e fetiche articulado à vida sexual.

Diante dessa reflexão, é pertinente desenvolver possíveis inferências com a sociedade cultural vigente de maneira ampla. De forma particular, retrata a disputa afrontosa entre mulheres na disputa ilusória e vazia da beleza e feminilidade em prol da satisfação sexual associada ao prazer masculino e, não necessariamente de si própria. Essa questão revela a história literária imprimindo marcas textuais da menina em situações de perigo e objetivação em relação ao sedutor (lobo mau) que, de forma violenta, 
potencializa na menina a perda de sua identidade em detrimento da condição sexual que ainda está sendo, culturalmente, construída. A ausência de um amadurecimento no que tange ao construto de sua sexualidade genital, Chapeuzinho se torna refém da situação regressiva e constrangedora do lobo que, de forma direta, causa-lhe danos e, possíveis traumas sexuais.

O destino da personagem - devorada pelo lobo - intensifica o estereótipo conciliado ao processo punitivo (aprender a lição) mediante ao ato de desobediência em escolher o "caminho" diferente do que foi orientado por sua avó. Há, aqui, marcas textuais da figura feminina que é suscetível ao processo de manipulação e sedução.

Depois de ter saciado o apetite, o lobo voltou para a cama, adormeceu e começou a roncar, fazendo um barulho fenomenal. Um caçador, que naquele momento estava passando em frente à casa, ouviu o barulho e pensou: "Como pode uma velhinha roncar desse jeito? Melhor verificar". Então ele entrou na casa e, ao chegar à cama, deparou-se com o lobo, a quem procurava havia tempo. Ele deve ter comido a avó, pensou, e talvez ainda seja possível salvá-la, por isso é melhor não atirar. Então, buscou a tesoura e cortou a barriga do lobo. Assim que deu os primeiros cortes, avistou chapeuzinho vermelho brilhando, e depois de mais uns cortes a menina saltou para fora dizendo: "Nossa que susto. Estava tão escuro na barriga do lobo". Logo depois, a avó também saiu com vida. Chapeuzinho correu para buscar pedras bem pesadas, que eles colocaram na barriga do lobo, e, quando ele acordou e quis ir embora, as pedras pesaram tanto que acabou caindo morto. Os três ficaram muito felizes. O caçador tirou a pele do lobo, a avó comeu o bolo e bebeu o vinho que a neta levara, a Chapeuzinho Vermelho, que estava feliz por ter escapado, prometeu a si mesma: "De agora em diante, não vou mais sair do caminho nem entrar na floresta sozinha, quando a minha mãe não deixar" (GRIMM, 2018, p. 107).

Carneiro e Gémes (2018) reforçam que essa situação da menina, em um sistema disciplinar sem um "salvador" ou herói, suprime o resgate frente ao perigo. A representação do personagem lenhador, no conto, evidencia outra concepção da masculinidade adulta realçada pela bondade e prática de heroísmo na captura e salvação da menina e sua avó. Assim, Orenstein (2002) declara que, devidamente, resguardada e reprimida, a menina terá seu futuro assegurado: o final feliz funcionará como o selo de competência protetiva do reprodutor masculino sobre a feminino (criança) e, promove um olhar crítico sobre um aspecto subjetivo e abrangente.

Mediante a situação vivenciada pela personagem, há o reconhecimento de sua sexualidade no processo de constituição corporal de suas regras e limites, mesmo que isso tenha lhe custado experienciar uma situação sexual traumática e intimidadora.

Destarte, o conto incita-nos, enquanto profissionais educacionais, a buscar uma formação emancipatória à luz de uma experiência crítica do pensar, no sentido de que haja uma ampliação do olhar pelas janelas da diversidade, do respeito e da quebra de paradigmas e práticas disciplinadoras. Esse 
processo pode se desenvolver desde a primeira infância no sentido de estimular as crianças, pelo ensino, ao processo de busca para além do aparente, do que é confortável saber por mediação de uma "pedagogia da submissão" em detrimento de um contexto social disciplinar e embrutecedor da subjetividade humana.

A morte sofrida pelo lobo, de forma dolorosa e cruel, desponta em um ato de revolta e brutalidade do "lenhador" mediante a situação violentamente traumática vivida por Chapeuzinho e sua avó (ROCHA, 2010). E, mesmo diante de tal feito, toda a situação de exposição e aniquilação da "inocência" da menina tem seu desfecho romanticamente marcado pela palavra mágica: "E viveram felizes para sempre". Logo, a justiça no final revelada pela atitude de crueldade da menina (outrora inocente) potencializa a moral: só é possível viver o final feliz, quando sobre a maldade houver a punição, mesmo que haja outros perigos mundo afora, ou seja: "se vence o mal com o mal", mas um ato de maldade que se justifica e se naturaliza como estratégia de liberdade e felicidade.

O conto focaliza os olhares vigilantes do século XVII em relação à sexualidade das mulheres, assim como ressaltado por Witzel (2012). Essa sexualidade evidencia as relações entre poder e saber, especificamente, sobre o corpo feminino firmado pela violência da feminilidade. Em Foucault, o conto é, desse modo, um documento arqueológico e histórico das relações do poder disciplinar em detrimento da produção de corpos dóceis correlacionados à sexualidade das mulheres

Por mediação de Chapeuzinho Vermelho, o conto pode ser considerado um procedimento da microfísica do poder, na medida em que joga exatamente com a eficiente relação entre gratificação e sanção, ou seja, qualquer comportamento que ela tenha será gratificado ou sancionado perante sua conduta. Por Chapeuzinho Vermelho ter infligido a lei moral na relação indissociável do discurso, a interdiscursividade nos mostra que a liberdade da mulher na sociedade é vista como perigosa e, ao mesmo tempo frágil, merecendo a sanção e a disciplina (WITZEL, 2012). Isto posto, na reconstrução dessa identidade para a efetivação de um poder associado às diferenças como identificação das subjetividades humanas, anula as sanções normalizadoras do ser e do direito de saber sobre si.

\section{Considerações finais}

Ao retomar o objetivo geral do texto que consistiu em compreender sobre o conceito de sexualidade em Foucault, a fim de identificar suas relações com o conto literário de Chapeuzinho Vermelho, possibilitou-nos um repensar acerca dos contos literários desenvolvidos em contextos escolares (educação infantil e anos iniciais do ensino fundamental) e, especificamente o conto supracitado no sentido de refletirmos sobre os paradigmas moralmente constituídos e propiciadores da repressão sexual. 
Os referenciais de análise desenvolvidos no texto, demarcam reflexões sobre o conceito de sexualidade de uma época histórica que eclode na sociedade atual regida pelos ditames normativos e de moralidade. Há, desse modo, a necessidade de uma ressignificação do olhar, em prol de novos horizontes formativos em relação ao conceito sobre sexualidade em detrimento de uma educação critica pautada nas premissas foucaultianas.

Por conseguinte, a sexualidade "faz parte da vida, está presente desde os primórdios da existência e se manifesta de diferentes formas, dependendo da etapa de desenvolvimento em que se encontra o indivíduo" (TAQUETTE, 2015, p. 26). Enquanto expressão social e histórica, a sexualidade é construída culturalmente e está relacionada às características dos indivíduos, auxiliando no processo de definição de suas subjetividades humanas.

A partir da história da repressão sexual e do controle social do corpo e com o corpo, a sociedade (séculos XVII, XVIII e XIX) investiu no corpo como uma realidade biológica que, precisa ser reorganizado na conjuntura contemporânea, em prol de uma constituição histórica envolvida pelos direitos de saber e poder e, principalmente, pelo direito ao respeito. Assim sendo, o direito ao respeito propriamente dito precisa ser desenvolvido em espaços educacionais com ações docentes comprometidas com a subjetividade humana e a singularidade dos corpos em suas diferenças. A ação educativa, nesse prisma, pode ser desenvolvida por meio da reconstrução e reelaboração do texto literário na escola, desmistificando para além da aparência, em busca da essência do que está sendo lido ou contado em sala de aula. Há, ainda, a necessidade de elaboração de novos contos pelas crianças e professores por meio de outras possiblidades de interpretações sobre as histórias, contos populares, textos literários e demais tipos de gêneros textuais.

É necessário entender que não há problema em continuar com a leitura do conto clássico no contexto da educação infantil e anos iniciais, desde que o mesmo não seja apenas repassado no sentido técnico da questão e de maneira ideológica e excludente, mas de maneira crítica e reflexiva. Para tanto, há a necessidade de uma formação docente fundamentada nos pressupostos críticos e emancipadores do saber, para além da reprodução servil e disciplinada do conhecimento.

Em Foucault, há a possibilidade de ressignificação do que vem sendo cristalizado em relação ao conceito de sexualidade, pelo confronto e resistência às normativas na sociedade disciplinar e, especificamente, cabe a escola e ao professor a tarefa de pensar em um espaço formativo pautado na multiplicidade e no respeito à subjetividade humana e, não necessariamente, em um "ideal" de ensino ou em uma única e exclusiva forma de comportamento humano.

\section{Referências}


CANDIOTTO, Cesar. Foucault e a crítica da verdade. 2. Ed. Belo Horizonte: Autêntica Editora; Curitiba: Champagnat, 2013.

CARNEIRO; Cassiana Ximenes; GÉMES, Márton Tamás. A subversão do estereótipo Chapeuzinho Vermelho no conto A Companhia dos Lobos de Angela Carter. Revista Homem, Espaço e Tempo, v. 12, n. 2. Ceará, 2018.

CORSO, D. L. e CORSO, M. Fadas no divã: psicanálise nas histórias infantis. Porto Alegre: Artmed, 2006.

FILHA, Constantina Xavier. Era uma vez uma princesa e um príncipe...: representações de gênero nas narrativas de crianças. Estudos Feministas, p. 591-603, 2011.

FOUCAULT, Michel. A arqueologia do saber. Tradução Luiz Felipe Baeta Neves. $8^{\mathrm{a}}$ edição, Rio de Janeiro: Forense Universitária, 2017.

FOUCAULT, Michel. A ordem do discurso. Edições Loyola, 24a edição, São Paulo, 2014.

FOUCAULT, Michel. História da sexualidade. v. 1. A vontade de saber. In: História da sexualidade. v. 1. A vontade de saber. Paz \& Terra, 2015.

FOUCAULT, Michel. Vigiar e Punir: nascimento da prisão. $20^{\circ}$ edição. Tradução de Raquel Ramalhete. Petrópolis: Vozes, 1996.

GROS, Frédéric. Desobedecer. Tradução: Célia Euvaldo. Ubu Editora, 224 pp. Coleção Exit. São Paulo, 2018.

GRIMM, Irmãos. Contos maravilhosos infantis e domésticos/ Jacob Grimm e Wilhelm Grimm; tradução de Christine Röhrig; posfácio de Marcus Mazzari - São Paulo: editora 34, 2018 (1ª edição). 624 p. (coleção fábula). 2018.

ORENSTEIN, Catherine. As múltiplas vidas de "Chapeuzinho Vermelho". Estudos Feministas, Florianópolis, 2003.

REDEL, Elisângela; MARTINY, Franciele Maria. Da palavra à imagem: a temática da sexualidade e sua função formadora em Rotkäppchen. Revista Trama, v. 11, $\mathrm{n}^{\circ}$. 21. Marechal Cândido Rondon Paraná, 2015.

ROCHA, Waldyr Imbroisi. As várias histórias de Chapeuzinho Vermelho: repressão e moral nos contos de fadas. Revista Anagrama: Revista Científica Interdisciplinar da Graduação. $4^{\mathrm{a}}$ ed. - São Paulo, 2010.

SILVA, Ivaneide Vieira. Complexo de cinderela: A imagem da mulher no conto de Perrault. ComSertões - Revista de Comunicação e Cultura no Semiárido, [S. 1.], v. 1, n. 4, jan. 2017.

SOARES, Michelle Gomes. RINCON, Neire Márzia. Marcas do erotismo no conto Chapeuzinho Vermelho. Mediação, Pires do Rio - GO, v. 12, n. 1, p. 171-182, 2017.

SOUZA, Liliane Lima de. FERNANDES, Francisco Felipe Paiva. A performatividade do gênero nos enunciados fílmicos infantis: o efeito de um discurso heteronormativo. II Congresso Nacional de Educação. Campina Grande - PB, 2015.

PINTO, Célia Regina Jardim. Elementos para análise de discurso político. Revista Barbarói, $24^{\mathrm{a}}$ edição. Santa Cruz do Sul, 2006.

TAQUETTE, S.R. Homossexualidade e adolescência: Sob a ótica da Saúde. Editora da Universidade do Rio de Janeiro. Rio de Janeiro, 2015.

WITZEL, Denise Gabriel. Discurso, poder e a moralidade (in) desejada da Chapeuzinho Vermelho na mídia. Caderno Espaço Feminino. Uberlândia, MG. 2012. 
Recebido em: 29/04/2020

Aceito em: 04/08/2020

\section{Notas}

\footnotetext{
${ }^{\text {i }}$ Mestre em Educação pela Universidade Estadual de Londrina. E-mail: ravelli_28@hotmail.com Londrina. ORCID: https://orcid.org/0000-0001-5706-9373

ii Pós-Doutora em Educação pela Universidade Paulista Julio de Mesquita Filho. Professora Associada do Departamento de Educação e do Programa de Pós-Graduação Mestrado e Doutorado em Educação da Universidade Estadual de Londrina. Coordenadora da Comissão de Pesquisa do Depto de Educação da UEL. Líder do GEPEITC - Grupo de Estudos e Pesquisa em Educação, Infância e Teoria Crítica da UEL E-mail: marta.furlan@yahoo.com.br Londrina. ORCID: https://orcid.org/0000$\underline{0003-2146-2557}$
}

iii Doutora em Educação pela Universidade Estadual de Campinas. Docente adjunta da Universidade Estadual de Maringá no programa de Pós-Graduação em Educação. E-mail: gccalsa@hotmail.com Maringá. ORCID: https://orcid.org/0000-0003$\underline{2581-2948}$

iv A dissertação intitulada é: "Da repressão sexual ao direito de ser e saber: agora é nossa vez" defendida em 28 de fev. 2020 na Universidade Estadual de Londrina.

v É evidente que os níveis de domínio do discurso no século XVIII apresentam uma notoriedade inversa à do século passado, agora as novas elocuções sobre o sexo tornam-se específicas adentro daquela normativa que abrange o discurso indecente tencionando reverter à censura (FOUCAULT, 2015, p. 22).

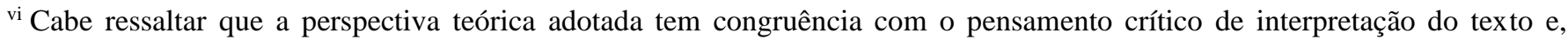
caracteriza-se em meados dos séculos XV e XVI na Europa Ocidental, como "uma maneira de pensar, de dizer, igualmente de agir, uma relação com o que existe, com o que sabemos e fazemos, uma relação com a sociedade, com a cultura, com os demais [...]" (FOUCAULT, 2017, p. 36). Entretanto, há possibilidade para o olhar analítico fundado em outras bases teóricas críticas.

vii $\mathrm{Na}$ atualidade, as dores e traumas leves ou em uma profunda escala podem afetar a autoimagem, autoestima, o desenvolvimento intelectual, culpa, sentimento de não pertencimento, inaptidão e isolamento, entre outros, comprometendo significativamente suas relações interpessoais. 